\title{
Tendencies of using and quality improving products made of fibrous metal composites for structural elements of power engineering under environmental conditions
}

\author{
Alexey Oleshko* \\ State Educational Institution of Higher Education Moscow Region «University of technology», \\ Korolev, Moscow Region, Russia
}

\begin{abstract}
This paper discusses the relevance of a composite material based on a titanium alloy reinforced with fibers of silicon carbide. The development trends are given for the production of Ti-SiC composite material both abroad and in Russia. Ways to improve the quality of manufactured products from $\mathrm{Ti}-\mathrm{SiC}$ in the development of heat-stressed parts made of fiber-reinforced metal composites for power engineering in terms of the environment are defined in this paper.
\end{abstract}

Keywords: fibrous metal composites, quality of products, power engineering, power machines, environment

\section{$1 \quad$ Introduction}

Metal composite materials (MCM) based on heat-resistant fibers and heat-resistant matrices for structural elements of power plants have unique specific strength and stiffness characteristics at elevated operating temperatures. According to these indicators, MCM has no analogs among traditional structural metal materials of the lightweight class - aluminum and titanium alloys. [1-3].

MCMs based on titanium and silicon carbide fibers (Ti-SiC) are the most promising materials in this segment. The functional assignment of the components in the material is distributed as follows. Silicon carbide fibers take up applied loads; provide increased strength and stiffness of MCM. Titanium provides heat resistance of the matrix material at elevated operating temperatures of MCM. The material, in addition to its high heat-resistant characteristics (operating temperature of about $600 \mathrm{oC}$ ), also has high mechanical properties, but only in the direction of reinforcement - along SiC fibers. This has to be taken into consideration at the stage of developing Ti-SiC structures. A distinctive feature of silicon carbide fibers is high heat resistance, superior to other non-metallic fibers in strength at temperatures above $400^{\circ} \mathrm{C}$ with a relatively low density $(3,9 \mathrm{~g} / \mathrm{cm} 3)$, which can

\footnotetext{
*Corresponding author: korolev2005-06@mail.ru
} 
reduce the mass and increase the rigidity of the elements of load-bearing structures under environmental conditions [4-6].

\section{$2 \quad$ Materials and methods}

The method of regression analysis was used to solve the problems of improving the quality of products made of fibrous metal composites, on the basis of which graphical dependencies of the main indicators of the quality of products and production parameters were obtained, software packages (Excel) for processing experimental data.

\section{$3 \quad$ Results and discussion}

The metal composite of the Ti-SiC system is a complex object for manufacturing, which is largely due to the need of using high temperatures (about $1000^{\circ} \mathrm{C}$ ) for plastic deformation and diffusion welding of titanium matrix layers during hot pressing of $\mathrm{Ti}-\mathrm{SiC}$ multilayer billet. Considering the high tendency of titanium alloys to oxidize at temperatures above $500{ }^{\circ} \mathrm{C}$, the processes of plasma spraying of titanium in the production of monolayer semifinished products and hot pressing of multilayer billets are carried out in a vacuum with a residual pressure of no more than $10-4 \mathrm{~mm} \mathrm{Hg}$ on specialized equipment. Using high temperatures in preparation for a metal composite is accompanied by the development of reaction-diffusion processes along the «titanium - SiC fiber» interface with the formation of brittle carbide and silicide phases. The interaction data in the Ti-SiC fiber system shows good chemical compatibility of the components up to temperature of about $800{ }^{\circ} \mathrm{C}$; a sufficiently high level of material strength is maintained only for a period of 2 to 3 hours at temperatures from $850{ }^{\circ} \mathrm{C}$ to $950{ }^{\circ} \mathrm{C}$; a noticeable drop in strength begins after 30 to 60 minutes at temperatures from $1000{ }^{\circ} \mathrm{C}$ to $1200{ }^{\circ} \mathrm{C}$. Besides, there are residual thermal stresses in this zone that contribute to the emergence and development of microcracks in the matrix due to the difference in the values of the coefficients of linear thermal expansion of silicon carbide (4,7 $10-6$ deg-1) and titanium (8,5 $10-6$ deg-1). Metal coatings, including multilayer ones, are applied to the fibers from the gas phase to reduce the tendency of the matrix alloy to crack, the components of which prevent chemical interaction and increase the plastic properties of the interface. To implement the technology of obtaining MCM Ti$\mathrm{SiC}$, preliminary production of a monolayer tape is required. There are various technological methods of manufacturing semi-finished products $\mathrm{Ti}-\mathrm{SiC}$ fiber [7-9].

The production of a semi-finished product is widely used with a volatile organic ashless binder connecting fibers with a matrix material in the form of a foil or powder. Titanium aluminide powders are used as the matrix material to increase the operating temperatures of Ti-SiC metal composites. The binder is distilled off in a gaseous form without decomposition (polystyrene) or decomposes into gaseous products (cyacrine, polyvinyl alcohol) under the action of heating during subsequent hot pressing [10-12].

Unconditional attention should be paid to technical solutions that provide a decrease in the temperature of hot pressing of a multilayer billet $\mathrm{Ti}-\mathrm{SiC}$ that not only simplifies the technology but also improves the quality of the metal composite. In US patent № 4847044 , namely the introduction of a softer metal such as aluminum into the matrix material [13]. Due to the soft metal flow, consolidation of the matrix and hardener (silicon carbide fibers) is ensured at relatively low temperatures. But this method cannot be used because of the application of the aluminum layer, the presence of which does not allow increasing the operating temperature higher than $400 \mathrm{oC}$.

Various options for manufacturing an intermediate semi-finished $\mathrm{Ti}-\mathrm{SiC}$ fiber are considered. The implemented approach in the production of boraluminium was chosen. 
Manufacturing includes two main operations: winding reinforcing fiber and adding matrix material by plasma spraying (in the atmosphere). However, titanium should be applied in a controlled atmosphere (vacuum) onto a drum with a wound monolayer of fibers. The purpose of the winding operation is to create an ordered monolayer row of silicon carbide fibers (Fig. 1).

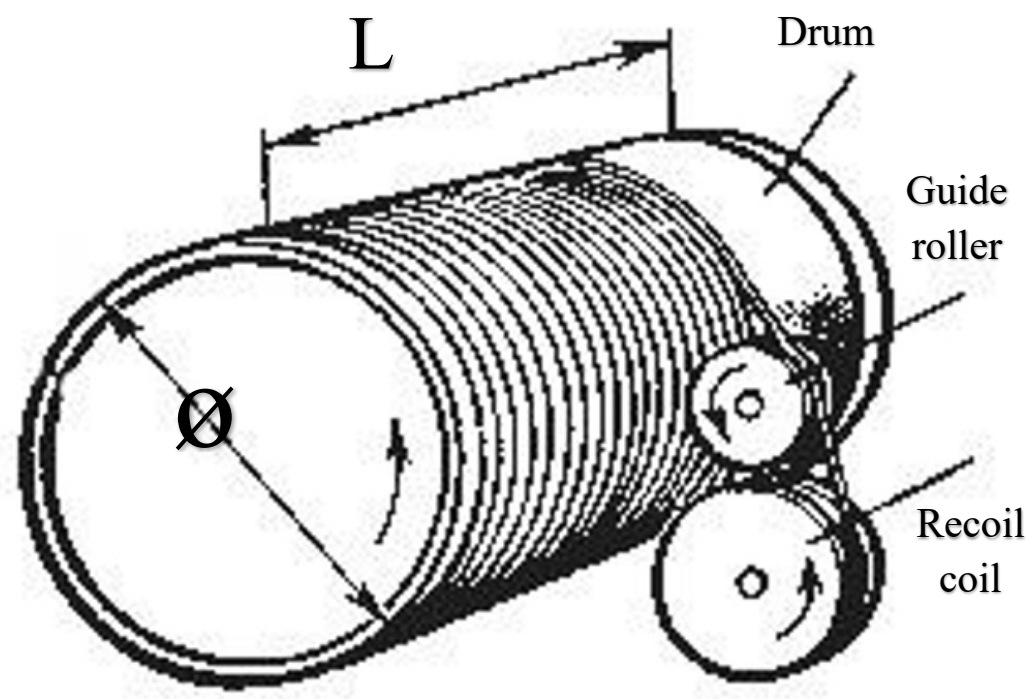

Figure 1 - Scheme for winding silicon carbide fibers on a drum

For winding silicon carbide fibers, the following equipment: a specialized winding machine equipped with a thread pulling mechanism and equipment - a special drum is used. An ordered monolayer of silicon carbide fibers is formed on the surface of the drum by winding, while the uniform distribution of the fiber is ensured by a groove made on the surface of the drum, into which the fibers are laid during winding. Drum dimensions diameter and height, determine the dimensions of the mono tape, respectively, the length and width. During winding, the thread drawing mechanism moves along the generatrix of the drum at a speed corresponding to the winding speed. Winding is carried out as follows. A coil of silicon carbide fibers is installed in the brackets of the recoil coil with the possibility of free rotation. The silicon carbide fiber is passed through the guide roller of the thread drawing device, and its end is fixed on the working surface of the drum. When the drum rotates, the thread drawing mechanism is activated, and the fiber from the coil is wound in a monolayer on the drum.

The quality and complexity of winding directly depend on the properties and condition of the supplied silicon carbide fibers. The most negative impact on the winding process is caused by fiber breaks, which usually occur for the following reasons: low strength of the fiber, the presence of factory glues on the fiber coil, production glues of the fiber during the winding process. Fiber breaks and factory gluing significantly slow down the winding process. In case of a break, it is necessary to stop the machine, wait until the drum stops completely, glue the ends of the fiber so that the gluing point is above the groove (made along the generatrix of the drum for subsequent cutting of the mono tape), manually lay 2-5 turns of the fiber and restart the machine. Factory gluing of pieces of fiber on the spool is removed during winding and requires the same measures as when breaking, therefore minimizing the number of gluing also helps to optimize the winding process. 
For optimizing the process of winding silicon carbide fibers, several experiments were carried out, based on the results of which, graphical models of the dependence were constructed (Fig. 2).

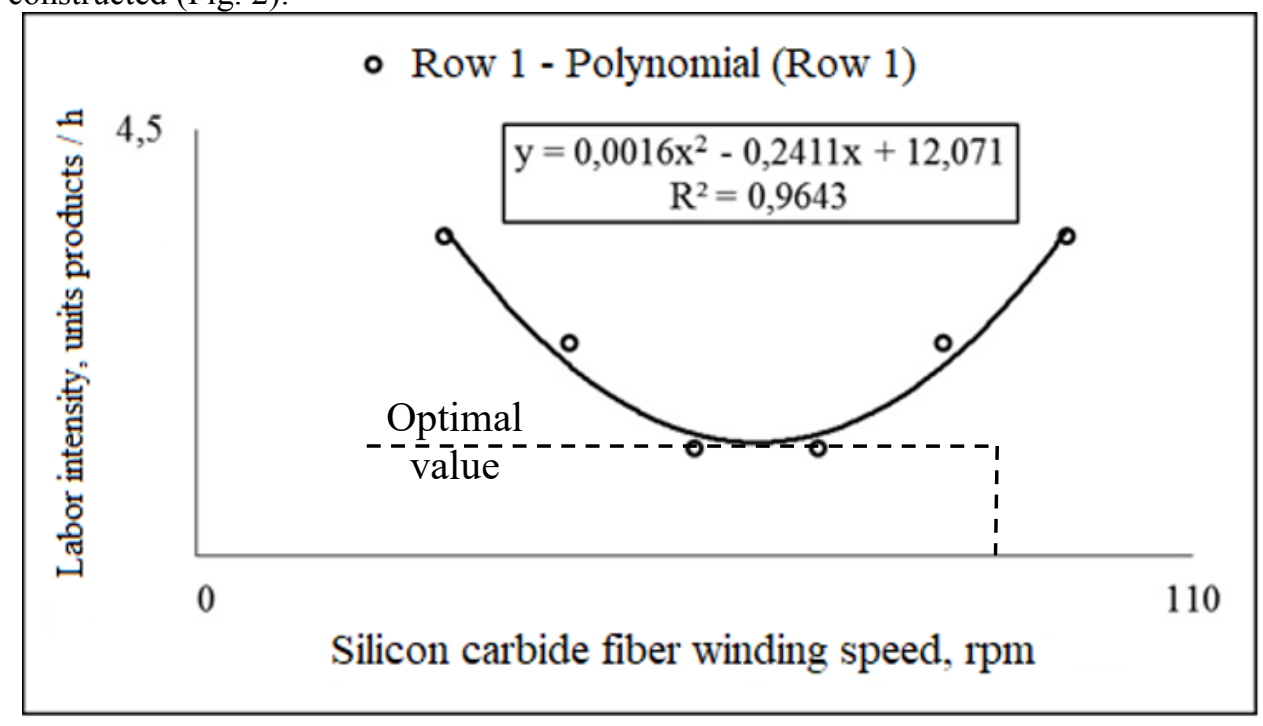

a

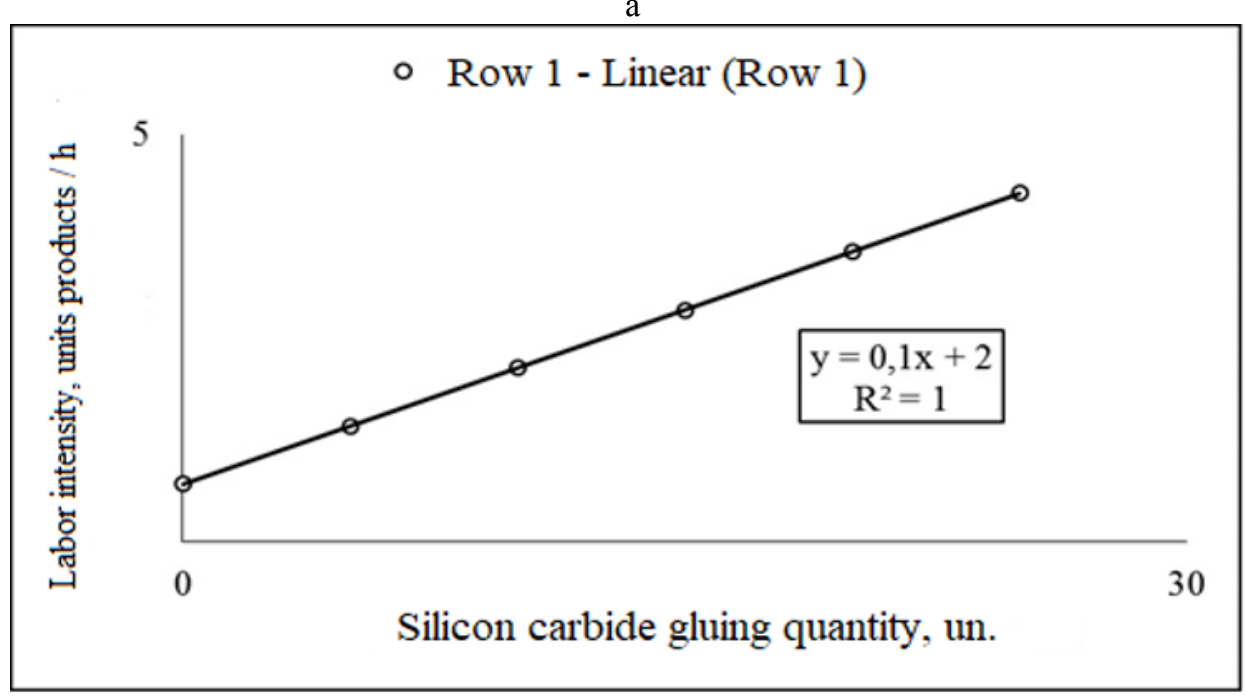

$\mathrm{b}$

Figure 2 - Regressive dependence [14]: a - typical dependence of the duration of the winding process on the speed of rotation of the drum; $b$ - justification for increasing the duration of the winding operation

The regression model (Fig. 2a) determines the optimal value of the winding speed of silicon carbide fibers, which was characterized by a quality indicator (spent time per unit of production) during the rewinding of the fiber to a specialized drum. The regression model (Fig. 2b) shows a linear ratio of the quality indicator (spent time per unit of production) to the number of glues produced during the winding of silicon carbide fibers, a growth of the number of glues leads to an increase in time. 
In turn, improving the quality of products made of fibrous metal composites, in particular from $\mathrm{Ti}-\mathrm{SiC}$, is an urgent task when using them in the composition of materials for supporting structures of power plants of spacecraft, where a sufficiently high level of mechanical properties is required at elevated operating temperatures. The main properties of composite materials are laid down at the technological level of production. Therefore, it is necessary to determine through improving the quality of products made of Ti-SiC: development of rational parameters of technological operations, taking into account the least degradation of the properties of each of the components and an increase in the initial physical and mechanical indicators of the quality of reinforcing fibers.

At the end of the winding process, the drum with a monolayer of silicon carbide fibers formed on the surface enters the installation for plasma spraying of the matrix material. The purpose of the spraying operation is to form the required amount of matrix material in the form of a uniform layer on the fibers, while simultaneously fixing the order of their distribution achieved during winding. The production of a metal composite of the Ti-SiC system is associated with limited chemical compatibility between titanium and silicon carbide, with a high melting point of titanium $\left(1400{ }^{\circ} \mathrm{C}\right)$ as well. Despite being the advantage of a heat-resistant matrix, this simultaneously causes a high temperature required for plastic deformation and diffusion welding from $800{ }^{\circ} \mathrm{C}$ to $1000{ }^{\circ} \mathrm{C}$. That negatively impacts the strength characteristics of $\mathrm{SiC}$ fibers. The method of applying the coating by plasma spraying in a dynamic vacuum is shown below (Fig. 3).

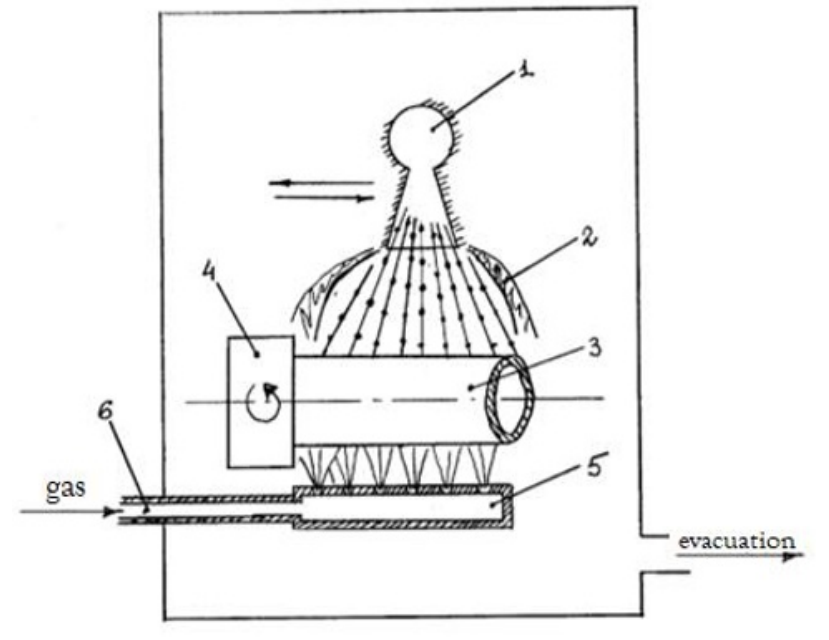

Figure 3 - Deposition of titanium on the drum [15]: 1 - plasmatron, which expires on plasma with particles of the sprayed substance; 2 - the hanging shock wave arising in underexpanded jet of plasma emanating into the sparse atmosphere, 3 - detail, the surface of which is plated; 4 - holder, rotating the item, 5 - the system of holes or slits, 6 - gas pipeline

A stream of plasma with sprayed powder is directed to the surface of a rotating part located in the area of reduced pressure. The inleaking gas is pumped out to maintain a dynamic vacuum. The rotating part is blown with cooling gas from the side opposite to the plasma flow. Cooling gas blowing is carried out without mixing the cooling gas and plasma flows and from a distance of less than half the diameter of the rotating part. The total pressure of the cooling gas is provided less than or equal to the total pressure of the plasma. The technical result consists in obtaining a sprayed coating in an amorphous state, which, in turn, applies coatings of greater thickness to parts. 
The method of spraying the material without blowing gas has a drawback - overheating of the part to be coated is possible during plasma spraying. As a result, it is not possible to obtain a coating of the required thickness. Meanwhile, the occurring crystallization of the sprayed substance in the coating does not improve its performance. This is caused by less intense heat exchange with the surrounding gaseous medium due to its reduced density in a rarefied medium in comparison with deposition in the atmosphere. Besides, the slow drop in the braking temperature along the jet flowing into the rarefied space, compared to the jet flowing into the atmosphere, also contributes to overheating of the part when coatings are sprayed on it. A method for applying coatings by plasma spraying in a dynamic vacuum can be used in plasma metallurgy, in the construction of elements of power plants under environmental conditions.

Several experiments were performed on the selected method for obtaining the intermediate semi-finished product Ti-SiC and graphically obtained dependencies (Fig. 4).

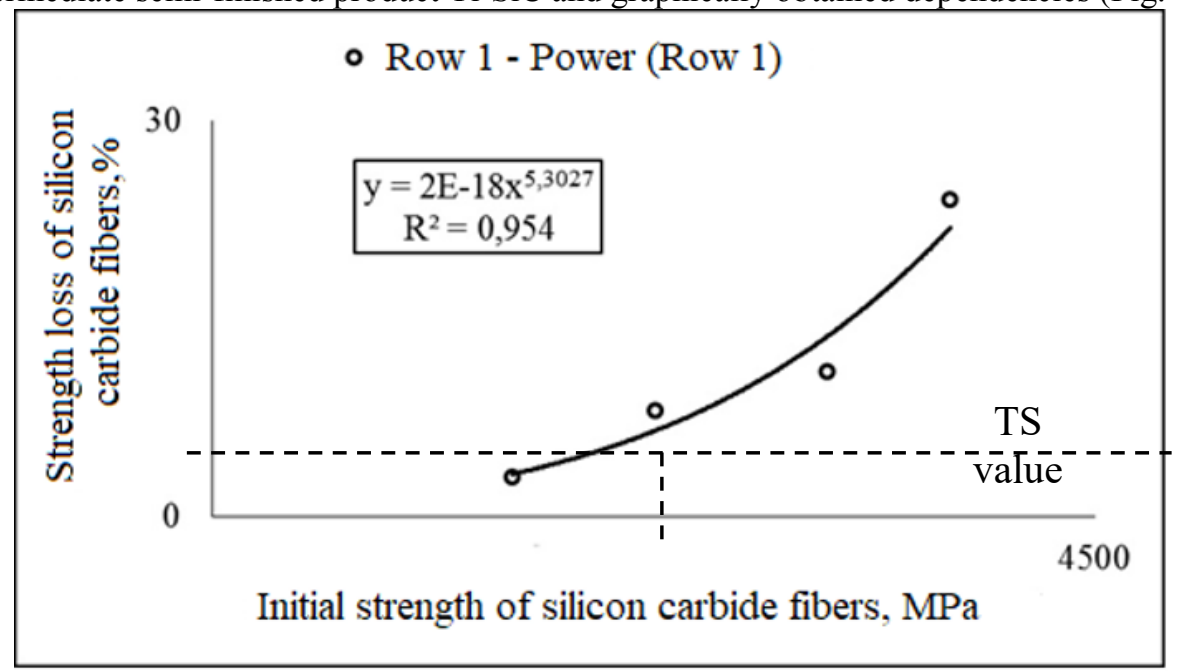

a

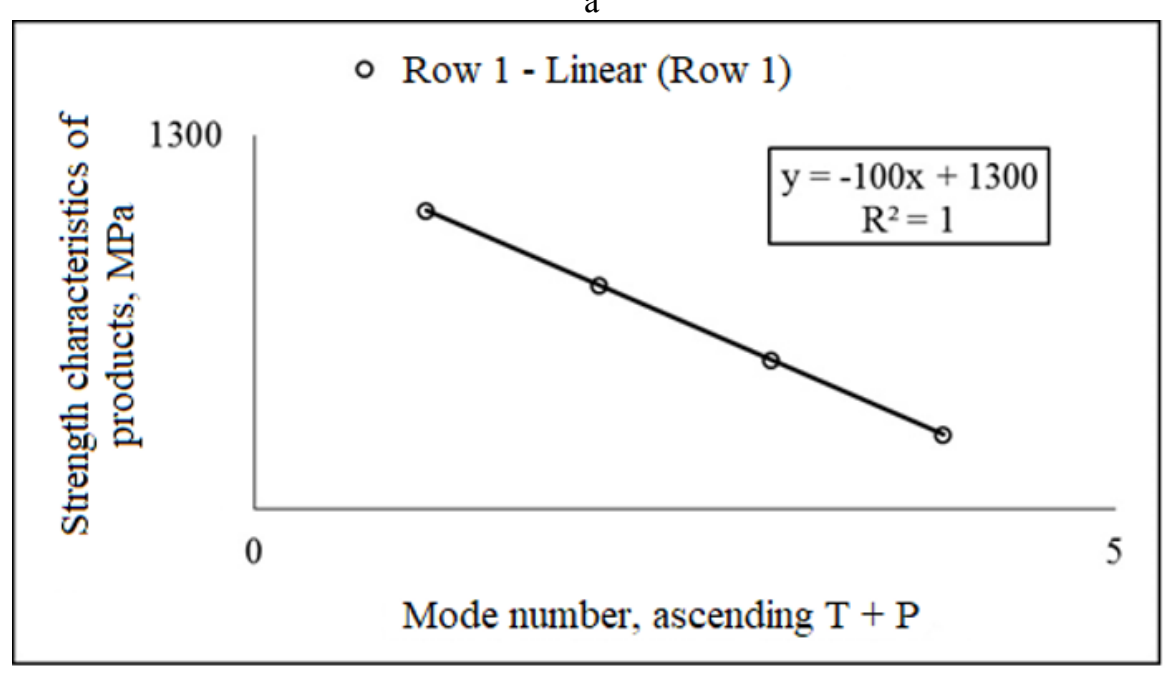

b

Figure 4 - Regressive dependence [14]: a - typical dependence of the strength loss of fibers on thermo-mechanical treatment; $b$ - justification of the tendency to reduce the tensile strength 
The regression model (Fig.4a) determines the maximum value of the initial strength of silicon carbide fibers relative to the quality index (maximum value of the strength loss according to technical specifications (TS)) after plasma spraying of the matrix. The minimum value of the initial strength of silicon carbide fibers is regulated by the technical condition. The regression model (Fig.4b) shows a linear ratio of the quality index (tensile strength characteristics) to the change in the matrix deposition mode towards an increase in temperature $(\mathrm{T})$ and mechanical impact $(\mathrm{P})$ on silicon carbide fibers, an increase in $\mathrm{T}+\mathrm{P}$ values leads to decrease in strength.

Further, the intermediate semi-finished product is assembled into a multi-layer billet by layering, for subsequent consolidation of which the methods of hot pressing in a vacuum and gas-static pressing are used, during which the monolayers are welded and the connection between the fibers and the matrix material is formed. The effect of hot pressing modes of MCM Ti-SiC results from the same linear relationship of strength characteristics as during plasma deposition.

\section{Conclusion}

The described approaches to obtaining a metal composite material Ti-SiC and the developed graphic models can be applied in the development of heat-stressed elements from fibrous metal composites for power plants used under environmental conditions, thereby ensuring the following conditions:

- obtaining a fibrous metal semi-finished product in a protective environment reduces the impact of the environment on the properties of elements of power machines;

- typical dependences of the production of fibrous metal composites determining the optimal values for their production by the speed of fiber winding and the addition of the matrix by plasma spraying in a dynamic vacuum are shown.

\section{References}

1. C. González, J. LLorca, Micromechanical modeling of deformation and failure in Ti6Al-4V/SiC composites, Acta Materialia 49 (2001), pp. 3505-3519.

2. C. González, J. LLorca, A.Weck, Toughness of fiber-reinforced titanium as a function of temperature: experimental results and micromechanical modeling, Acta Materialia 52 (2004).

3. D.B. Marshall, B.N. Cox, A.G. Evans, The mechanics of matrix cracking in brittlematrix fiber composites, Acta Metallurgica 33 (1985), pp. 2013-2021.

4. M.D. Thouless, A.G. Evans, Effects of pull-out on the mechanical properties of ceramic matrix composites, Acta Metallurgica 36 (1988), pp. 517-522.

5. B.S. Majumdar, T.E. Matikas and D.B. Miracle, Effects of the interface on local versus global load sharing behaviour in metal matrix composites under longitudinal tension. Proceedings of Layup the 11th International Conference of Composite Materials 1997 (ed M.L Scott), Gold Coast, Australia, 14-18th July, 1997. Woodhead Publishing Ltd, Paper 30, pp. 238-249.

6. M.P. Thomas, Longitudinal Tensile Behaviour of Titanium Metal Matrix Composites Produced by the Fibre-Foil Route, October 1997, TISICS Report: TI6-00587 (Defence Evaluation \& Research Agency, Farnborough, 1997).

7. M.P. Thomas, Tensile Properties of IMI 318 / SM1240 Titanium Metal Matrix Composite with Off-Axis Fibres, August 1997, TISICS Internal Report: TI6-00002 (Defence Evaluation \& Research Agency, Farnborough, 1997). 
8. C. Lissenden, Fiber-matrix interfacial constitutive relations for metal matrix composites, Composites: Part B, 30, 1999, pp. 267-278.

9. B.S. Majumdar and G.M. Newaz, Inelastic deformation of metal matrix composites: Plasticity and damage mechanisms, Philosophical Magazine, 66, 1992, Iss 2, pp. 187 212.

10. Kyle-Henney, S. Silicon carbide monofilament reinforced titanium composites for space structures a new material option / S. Kyle-Henney, S. Flitcroft, R. Shatwell, D. Gibbon, G. Voss, P. Harkness // University of Glasgow School of engineering. - 2012. -6 p. 20.

11. Neubauer, E. Metal matrix composites (MMCS) as high performance metallic material. Technical proposal / E. Neubauer, H.G. Wulz, Ch. Edtmaier, I. Agote, A. Merstallinger, G. Mozdzen, V. Liedtke, N. Stelzer, N. Gamsjäger // Aerospace and advanced composites. - 2013. - Volume 1. - 46 p.

12. Neubauer, E. Metal matrix composites (MMCS) as high performance metallic material. Financial, management and administrative proposall / E. Neubauer, H.G. Wulz, Ch. Edtmaier, I. Agote, A. Merstallinger, G. Mozdzen, V. Liedtke, N. Stelzer, V. Liedtke, N. Gamsjäger // Aerospace and advanced composites. - 2013. - Volume 2. - 102 p.

13. US 4847044. Method for producing an aluminide-based composite / ROCKWELL INTERNATIONAL. 18.04.1988.

14. Oleshko, A.Y. Development of mathematical models for determining the optimal parameters of the technological cycle operations for obtaining boraluminium tubular elements for loaded structures / A.Y. Oleshko, T.N/ Antipova // Structures made of composite materials - intersectoral scientific and technical journal. - 2017. - № 3(147). - P. 28-33.

15. RU 2586932. A method of applying a coating by plasma spraying in a dynamic vacuum / SSC RF FGUP «Research Center named after M.V. Keldysh». 10.06.2016. 